\title{
Study on Climate Changes for Flue-Cured Tobacco Growth in Chenzhou City of Hunan Province
}

\author{
Xiangzhen Kong1,2, Decheng $\mathrm{Li}^{1^{*}}$, Wujin $\mathrm{Li}^{3}$, Hongguang $\mathrm{Li}^{3}$, Yansong Xiao \\ ${ }^{1}$ State Key Laboratory of Soil and Sustainable Agriculture, Institute of Soil Science, Chinese Academy of Sciences, Nanjing, China \\ ${ }^{2}$ University of Chinese Academy of Sciences, Beijing, China \\ ${ }^{3}$ Chenzhou Tobacco Company of Hunan Province, Chenzhou, China \\ Email: xzkong@issas.ac.cn, ^dcli@issas.ac.cn
}

How to cite this paper: Kong, X.Z., Li, D.C., Li, W.J., Li, H.G. and Xiao, Y.S. (2020) Study on Climate Changes for Flue-Cured Tobacco Growth in Chenzhou City of Hunan Province. Agricultural Sciences, 11, 487-499. https://doi.org/10.4236/as.2020.115030

Received: February 9, 2020

Accepted: May 17, 2020

Published: May 20, 2020

Copyright $\odot 2020$ by author(s) and Scientific Research Publishing Inc. This work is licensed under the Creative Commons Attribution International License (CC BY 4.0).

http://creativecommons.org/licenses/by/4.0/

\begin{abstract}
Chenzhou city is the most typical region of Nanling Hill Ecological Zone of flue-cured tobacco with of aroma style of burnt sweet and pure sweet in China and is the largest planting region of flue-cured tobacco in Hunan province. It is of significance to study the changes of climatic parameters with time because climate is the most important factor in determining the growth, yield and quality of flue-cured tobacco. In this study, the data of climatic parameters including cumulative sunshine hours $(S)$, mean temperature $(T)$ and cumulative precipitation $(P)$ from 1952 to 2018 in Chenzhou were used to analyze their changes at the scales of year, whole field period and growing period of flue-cured tobacco. The results showed that at the scale of year, the cumulative $S$, mean $T$ and cumulative $P$ were ranged from $1029.0 \mathrm{~h}$ to $2072.1 \mathrm{~h}$, from $17.1^{\circ} \mathrm{C}$ to $19.5^{\circ} \mathrm{C}$ and from $897.1 \mathrm{~mm}$ to $2244.6 \mathrm{~mm}$, with the means of $1449.7 \mathrm{~h}, 18.1^{\circ} \mathrm{C}$ and $1482.5 \mathrm{~mm}$, respectively. At the scale of whole field period of flue-cured tobacco, the cumulative $S$, mean $T$ and cumulative $P$ were ranged from $298.1 \mathrm{~h}$ to $807.2 \mathrm{~h}$, from $21.2^{\circ} \mathrm{C}$ to $23.9^{\circ} \mathrm{C}$ and from $416.7 \mathrm{~mm}$ to $1102.7 \mathrm{~mm}$, with the means of $514.8 \mathrm{~h}, 22.3^{\circ} \mathrm{C}$ and $719.0 \mathrm{~mm}$, respectively. At the scale of growing period of flue-cured tobacco, the annual cumulative $S$ were ranged from $70.0 \mathrm{~h}$ to $257.2 \mathrm{~h}$, from $77.3 \mathrm{~h}$ to $322.5 \mathrm{~h}$ and from $131.2 \mathrm{~h}$ to $300.3 \mathrm{~h}$ in the periods of rooting, flourishing and maturing with the means of $127.8 \mathrm{~h}, 190.4 \mathrm{~h}$ and $197.2 \mathrm{~h}$, respectively. The mean temperatures were ranged from $14.2^{\circ} \mathrm{C}$ to $18.9^{\circ} \mathrm{C}$, from $22.2^{\circ} \mathrm{C}$ to $26.1^{\circ} \mathrm{C}$, and from $25.8^{\circ} \mathrm{C}$ to $29.6^{\circ} \mathrm{C}$ with the means of $16.4^{\circ} \mathrm{C}, 24.1^{\circ} \mathrm{C}$ and $28.0^{\circ} \mathrm{C}$, respectively. The annual cumulative $P$ were ranged from $69.9 \mathrm{~mm}$ to $553.9 \mathrm{~mm}$, from $133.1 \mathrm{~mm}$ to $485.6 \mathrm{~mm}$ and from $46.4 \mathrm{~mm}$ to $356.8 \mathrm{~mm}$ in the periods of rooting, flourishing and maturing with the means of $262.5 \mathrm{~mm}, 299.9 \mathrm{~mm}$ and $153.9 \mathrm{~mm}$,
\end{abstract}


respectively. At the year scale, cumulative $S$ annually decreased by $7.587 \mathrm{~h}$, mean $T$ annually increased by $0.02^{\circ} \mathrm{C}$, while cumulative $P$ changed irregularly with insignificantly increasing about by $0.184 \mathrm{~mm}$ annually. At the scale of whole field period of flue-cured tobacco, mean $T$ annually increased by $0.0195^{\circ} \mathrm{C}$, while both cumulative $S$ and $P$ changed irregularly with insignificantly decreasing by $1.64 \mathrm{~h}$ and $1.62 \mathrm{~mm}$ annually, respectively. At the scale of growing period of flue-cured tobacco, all climatic parameters changed irregularly except cumulative $S$ in significant positive compound function in the maturing period. Meanwhile, the slight decreasing tendency of cumulative sunshine hours and the slight increasing tendency of cumulative precipitation are disadvantageous while the slight increasing tendency of cumulative precipitation in the maturing period is positive for the growth and quality of flue-cured tobacco.

\section{Keywords}

Sunshine Hours, Temperature, Precipitation, Flue-Cured Tobacco, Chenzhou

\section{Introduction}

Chenzhou city, as the most typical region of Nanling Hill Ecological Zone of flue-cured tobacco with of aroma style of burnt sweet and pure sweet in China [1], is the largest planting region of flue-cured tobacco in Hunan province, accounting for about $1 / 3\left(2.67 \times 10^{4} \mathrm{hm}^{2}\right)$ of the total planting area of flue-cured tobacco in Hunan [2].

Most studies have shown that climate is the most important factor in determining the growth, yield and quality of flue-cured tobacco [3]-[8], meanwhile, there are some reports published on the climatic parameters in the planting area of flue-cured tobacco in Chenzhou, for examples, Kuang, by analyzing climatic characteristics and suitability assessment on tobacco-growing, thought the main meteorological problem is that more high temperature days in the mature period of flue-cured tobacco, easily induced the occurrence of "high temperature induced maturity" [9]. Rong, by studying the relationship between the climatic parameters with the growth of tobacco, considered that the temperature was feasible; the sunshine hours were unsuitable a little, while the rainfall was unfavorable in the transplanting period but appropriate in the periods of fast-growth and mature [10]. Chen et al. by analyzing the climate change characteristics during tobacco growing period, found low temperature and less light at transplanting and rooting stages and high temperature at the maturity stage contributed to the major limiting factor weakening the aroma style of flue-cured tobacco [11]. But these literatures were focused on analyzing of the characteristics of climatic indexes and their planting suitability for flue-cured tobacco without considering their changes over time [9] [10], or on their changes in the field-growing period of flue-cured tobacco without attention to their changes with time [11], moreover, 
they also lacked the recent climatic data beyond 2010. Therefore, in this study, we used the data of climatic parameters of Chenzhou from 1952 to 2018, studied further the changes of main climatic parameters with time in order to further provide scientific instruction for the prediction of climate and the field cultivation and management of flue-cured tobacco in Chenzhou.

\section{Methods and Materials}

\subsection{General Information of Tobacco-Growing Area in Chenzhou}

Chenzhou is located in the southeast of Hunan province, between $112^{\circ} 13^{\prime}$ to $114^{\circ} 14^{\prime}$ in east longitude and $24^{\circ} 53^{\prime}$ to $26^{\circ} 50^{\prime}$ in north latitude with a total area of $1.94 \times 10^{4} \mathrm{~km}^{2}$. It belongs to subtropical monsoon humid climate with the mean of annual sunshine hours of $1510.3-1764.3 \mathrm{~h}$, temperature of $15.4^{\circ} \mathrm{C}-18.3^{\circ} \mathrm{C}$, precipitation of $1320.3-1654.7 \mathrm{~mm}$ and frost-free season of $235-296 \mathrm{~d}$ [9]. The altitude of Chenzhou is ranged from $70 \mathrm{~m}$ to $2061.3 \mathrm{~m}$, and the landforms are complex and varied, with mountains and hills accounting for about $3 / 4$ of the total area. The main soil types are red soil, yellow red soil and paddy soil [12], and the total area of cultivated land is $30.96 \times 10^{4} \mathrm{hm}^{2}$ with the areas of $25.94 \times$ $10^{4} \mathrm{hm}^{2}$ for paddy fields and $5.02 \times 10^{4} \mathrm{hm}^{2}$ for dry fields [13]. Flue-cured tobacco is cultivated in both paddy fields and dry lands.

\subsection{Data Sources of Climatic Parameters}

The data of climatic parameters which include cumulative sunshine hours $(S)$, mean temperature $(T)$ and cumulative precipitation $(P)$ from 1952 to 2018 were provided by national meteorological observation station in Chenzhou. The field-growing period of flue-cured tobacco in Chenzhou is generally from March 15 to July 15, in which the rooting period is from March 15 to April 30, the flourishing period is from May 1 to June 15, and the maturing period is from June 15 to July 15 [11].

\subsection{Data Processing, Modeling and Mapping}

Microsoft Excel 2016 and IBM Statistics SPSS 20.0 were used for data processing, modeling and mapping. The statistics information of climatic parameters was listed, such as the rangeability, average, skewness and kurtosis of climatic parameters. Besides, the linear tendency of cumulative $S$, mean $T$ and cumulative $P$ at the scales of year and whole field period were exhibited. And the optimal regression models of cumulative $S$, mean $T$, and cumulative $P$ were used to explain the changing tendency in different growing periods of flue-cured tobacco. Moreover, the correlation analysis between climatic parameters at the scale of year, whole field period and growing period of flue-cured tobacco was done by pears on correlation coefficients.

\section{Results and Discussions}

\subsection{Statistics of Climatic Parameters}

Table 1 listed the statistics information of climatic parameters from 1952 to 2018 
in Chenzhou, including the statistical values of climatic parameters at the scale of year, whole field period and growing period of flue-cured tobacco.

At the scale of year, the annual cumulative $S$, mean $T$ and cumulative $P$ were ranged from $1029.0 \mathrm{~h}$ to $2072.1 \mathrm{~h}$, from $17.1^{\circ} \mathrm{C}$ to $19.5^{\circ} \mathrm{C}$ and from $897.1 \mathrm{~mm}$ to $2244.6 \mathrm{~mm}$, with the means of $1449.7 \mathrm{~h}, 18.1^{\circ} \mathrm{C}$ and $1482.5 \mathrm{~mm}$, respectively. At the scale of whole field period of flue-cured tobacco, the annual cumulative $S$, mean $T$ and cumulative $P$ were ranged from $298.1 \mathrm{~h}$ to $807.2 \mathrm{~h}$, from $21.2^{\circ} \mathrm{C}$ to $23.9^{\circ} \mathrm{C}$ and from $416.7 \mathrm{~mm}$ to $1102.7 \mathrm{~mm}$, with the means of $514.8 \mathrm{~h}, 22.3^{\circ} \mathrm{C}$ and $719.0 \mathrm{~mm}$, respectively. At the scale of growing period of flue-cured tobacco, the annual cumulative $S$ were ranged from $70.0 \mathrm{~h}$ to $257.2 \mathrm{~h}$, from $77.3 \mathrm{~h}$ to $322.5 \mathrm{~h}$ and from $131.2 \mathrm{~h}$ to $300.3 \mathrm{~h}$ in the periods of rooting, flourishing and maturing with the means of $127.8 \mathrm{~h}, 190.4 \mathrm{~h}$ and $197.2 \mathrm{~h}$, respectively. The mean temperatures were ranged from $14.2^{\circ} \mathrm{C}$ to $18.9^{\circ} \mathrm{C}$, from $22.2^{\circ} \mathrm{C}$ to $26.1^{\circ} \mathrm{C}$, and from $25.8^{\circ} \mathrm{C}$ to $29.6^{\circ} \mathrm{C}$, with the means of $16.4^{\circ} \mathrm{C}, 24.1^{\circ} \mathrm{C}$ and $28.0^{\circ} \mathrm{C}$, respectively. The annual cumulative $P$ were ranged from $69.9 \mathrm{~mm}$ to $553.9 \mathrm{~mm}$, from $133.1 \mathrm{~mm}$ to $485.6 \mathrm{~mm}$ and from $46.4 \mathrm{~mm}$ to $356.8 \mathrm{~mm}$ in the periods of rooting, flourishing and maturing with the means of $262.5 \mathrm{~mm}, 299.9 \mathrm{~mm}$ and $153.9 \mathrm{~mm}$, respectively.

Table 1. Statistics of climatic parameters from 1952 to 2018 in Chenzhou.

\begin{tabular}{|c|c|c|c|c|c|c|c|c|c|}
\hline \multicolumn{2}{|c|}{ Time } & Parameter & Min & $\operatorname{Max}$ & Mean & $\mathrm{SD}$ & CV\% & Ske & Kur \\
\hline \multirow{3}{*}{\multicolumn{2}{|c|}{ Year }} & $S(h)$ & 1029 & 2072.1 & 1449.7 & 211.7 & 14.6 & 0.34 & 0.28 \\
\hline & & $T\left({ }^{\circ} \mathrm{C}\right)$ & 17.1 & 19.5 & 18.1 & 0.6 & 3.28 & 0.60 & -0.31 \\
\hline & & $P(\mathrm{~mm})$ & 897.1 & 2244.6 & 1482.5 & 315.1 & 21.3 & 0.52 & -0.18 \\
\hline \multirow{3}{*}{\multicolumn{2}{|c|}{ Whole field period }} & $S(\mathrm{~h})$ & 298.1 & 807.2 & 514.8 & 78.9 & 15.3 & 0.47 & 2.21 \\
\hline & & $T\left({ }^{\circ} \mathrm{C}\right)$ & 21.2 & 23.9 & 22.3 & 0.7 & 3.0 & 0.39 & -0.44 \\
\hline & & $P(\mathrm{~mm})$ & 416.7 & 1102.7 & 719.0 & 157.1 & 21.9 & 0.32 & -0.24 \\
\hline \multirow{9}{*}{$\begin{array}{c}\text { Growing } \\
\text { period }\end{array}$} & Rooting & & 70.0 & 257.2 & 127.8 & 35.0 & 27.4 & 1.03 & 2.24 \\
\hline & Flourishing & $S(\mathrm{~h})$ & 77.3 & 322.5 & 190.4 & 46.0 & 24.1 & 0.01 & 0.43 \\
\hline & Maturing & & 131.2 & 300.3 & 197.2 & 32.7 & 16.6 & 0.28 & 0.28 \\
\hline & Rooting & & 14.2 & 18.9 & 16.4 & 1.1 & 6.9 & 0.10 & -0.63 \\
\hline & Flourishing & $T\left({ }^{\circ} \mathrm{C}\right)$ & 22.2 & 26.1 & 24.1 & 0.9 & 3.8 & 0.11 & -0.36 \\
\hline & Maturing & & 25.8 & 29.6 & 28.0 & 0.8 & 2.9 & -0.06 & -0.12 \\
\hline & Rooting & & 69.9 & 553.9 & 262.5 & 87.6 & 33.4 & 0.46 & 0.97 \\
\hline & Flourishing & $P(\mathrm{~mm})$ & 133.1 & 485.6 & 299.9 & 78.0 & 26.0 & 0.16 & -0.20 \\
\hline & Maturing & & 46.4 & 356.8 & 153.9 & 62.3 & 40.5 & 0.88 & 1.30 \\
\hline
\end{tabular}

Note: $\mathcal{S}$, sunshine hours; $T$, temperature; $P$, precipitation; Ske, skewness; Kur, kurtosis. The same below. 
C.V. (\%) values of the climatic parameters at all the time scales showed that both cumulative $S$ and $P$ were all in moderate variation (10\%-100\%), while mean $T$ were all in weak variation $(<10 \%)$ [14]. Skewness values of the climatic parameters showed that cumulative $S$, mean $T$ and cumulative $P$ were all in positive extreme skew distribution (Skewness $>0.3$ ) at the scales of year and whole field period [14]. But at the scale of growing period, cumulative $S$ in the rooting period, and cumulative $P$ in the periods of rooting and maturing were in positive extreme skew distribution. Cumulative $S$ in the maturing period, mean $T$ and cumulative $P$ in the flourishing period were all in positive skew distribution $(0.1<$ Skewness $\leq 0.3$ ), while cumulative $S$ in the flourishing period and mean $T$ in the periods of maturing were both in symmetric distribution $(-0.1<$ Skewness $\leq 0.1)$ [14]. Kurtosis values of cumulative $S$ showed that the probability density curves were all very flat (Kurtosis $<0.67)$ at the scales of year and the periods of flourishing and maturing, while were acute $(1.11<$ Kurtosis $\leq 3.0)$ at the scales of whole field period and the rooting period. Mean $T$ were all very flat at all scales and cumulative $P$ were all very flat at the scales of year and whole field period, but were normal $(0.90<$ Kurtosis $\leq 1.11)$ in the rooting period and acute in the maturing period [14].

\subsection{Annual Changes of Climatic Parameters}

Figures 1-3 showed that annual changes of cumulative $S$, mean $T$ and cumulative $P$ from 1952 to 2018 in Chenzhou. $S$ (Figure 1) exhibited a significant linear decreasing tendency $\left(S=-7.587 a+16510.167, R^{2}=0.488^{* *}\right)$ with an annual decrease of 7.587 h. But Figure 2, on the contrary, $T$ (Figure 2) showed a significant linear increasing tendency $\left(T=0.020 a-21.259, R^{2}=0.423^{* *}\right)$ with an annual increase of $0.02^{\circ} \mathrm{C}$. However, $P$ (Figure 3 ) changed irregularly with an insignificant increasing tendency $\left(P=0.184 a+1118.190, R^{2}=0.000\right)$.

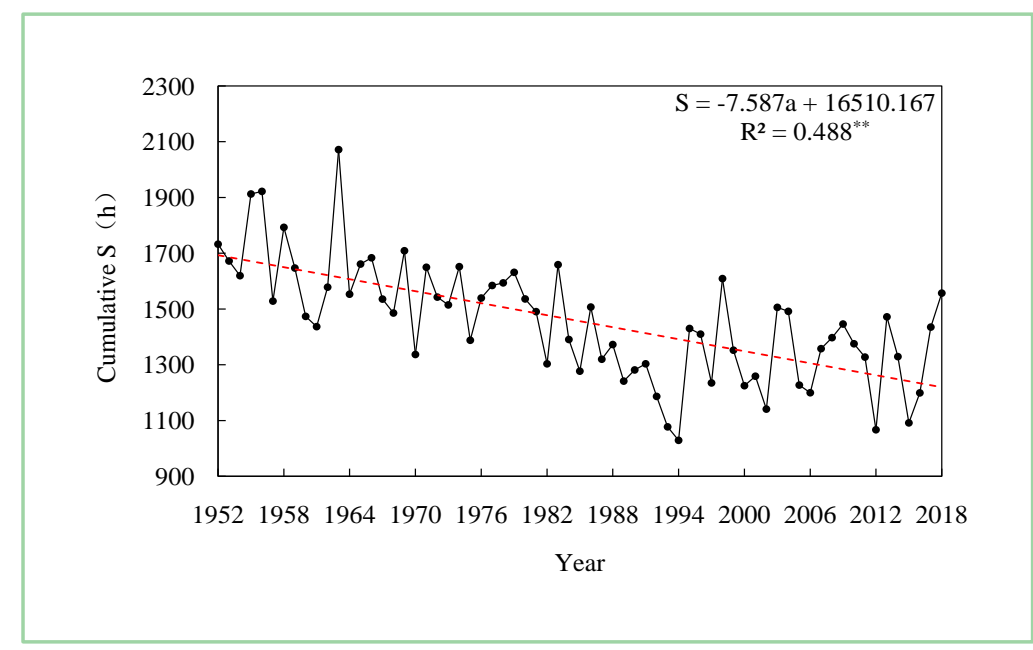

Figure 1. Annual cumulative sunshine hours from 1952 to 2018 in Chenzhou. Note: ${ }^{\star}$ and ${ }^{* *}$ indicate significant correlation in the levels of $p=0.05(n=67)$ and $p=0.01(n=67)$, respectively. The same below. 


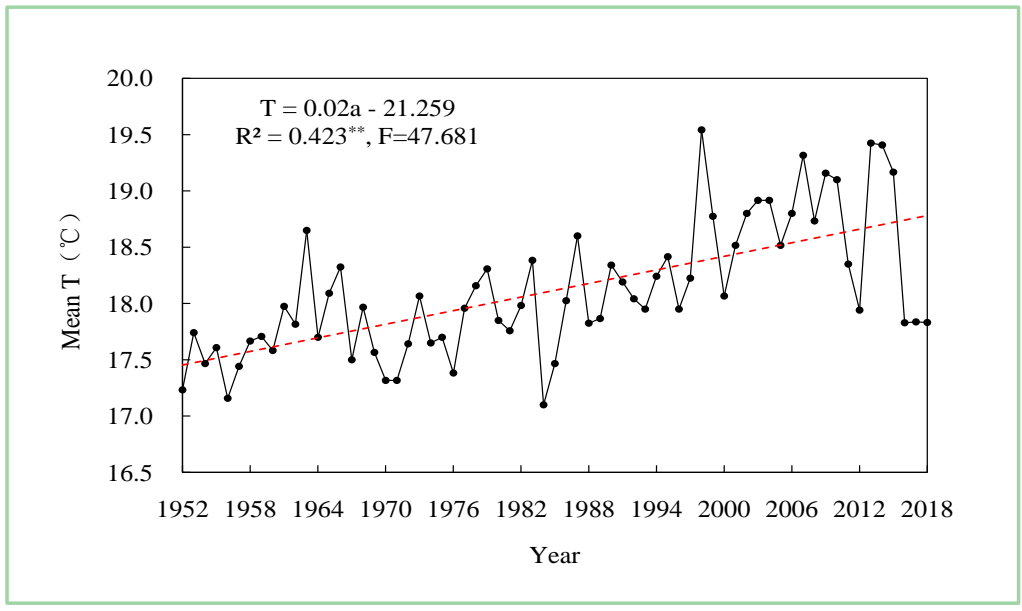

Figure 2. Annual mean temperature from 1952 to 2018 in Chenzhou.

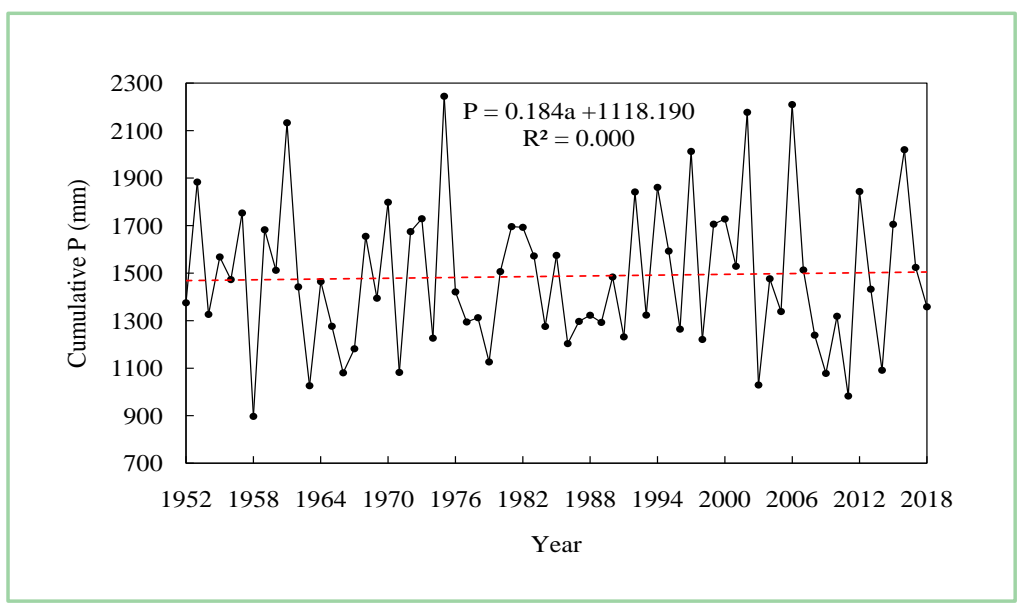

Figure 3. Annual cumulative precipitation from 1952 to 2018 in Chenzhou.

\subsection{Changes of Climatic Parameters in Whole Field Period of Flue-Cured Tobacco}

Figures 4-6 showed that changes of cumulative $S$, mean $T$ and cumulative $P$ in the whole field period of flue-cured tobacco from 1952 to 2018 in Chenzhou. Only the mean $T$ (Figure 5) showed a significant linear increasing tendency ( $T=$ $\left.0.0195 a-16.388, R^{2}=0.325^{* *}\right)$ with an annual increase of $0.0195^{\circ} \mathrm{C}$, while both cumulative $S$ (Figure 4 ) and $P$ (Figure 5) changed irregularly, but generally with an insignificant decreasing tendency $\left(S=-1.64 a+3770.1, R^{2}=0.164 ; P=\right.$ $\left.-1.6232 a+3941, R^{2}=0.041\right)$.

\subsection{Changes of Climatic Parameters in Different Growing Periods of Flue-Cured Tobacco}

Figures 7-9 and Table 2 showed the changes and the optimal regression models of cumulative $S$, mean $T$, and cumulative $P$ in different growing periods of flue-cured tobacco from 1952 to 2018 in Chenzhou, which showed all climatic parameters changed irregularly in different growing periods except cumulative 
$S$ was in significant positive compound function in the maturing period ( $S=$ $\left.1352021.777 \times 0.996^{\mathrm{a}}, R^{2}=0.268^{*}\right)$. In general, cumulative $S$ showed an insignificant positive $S$ function in the rooting period $\left(R^{2}=0.067\right)$, insignificant negative quadratic function in the flourishing period $\left(R^{2}=0.025\right)$. Mean $T$ showed an insignificant positive cubic function in the rooting period $\left(R^{2}=0.180\right)$, insignificant positive power function in the flourishing period $\left(R^{2}=0.176\right)$ and insignificant negative inverse function in the maturing period $\left(R^{2}=0.049\right)$. Cumulative $P$ showed an insignificant positive exponential function in the rooting period $\left(R^{2}\right.$ $=0.037)$ and insignificant positive inverse function in the periods of flourishing and maturing ( $R^{2}=0.029, R^{2}=0.014$, respectively).

\subsection{Correlation between Climatic Parameters}

Table 3 listed the Pearson correlation coefficients between climatic parameters at the scales of year, whole field period and growing period from 1952 to 2018 in Chenzhou.

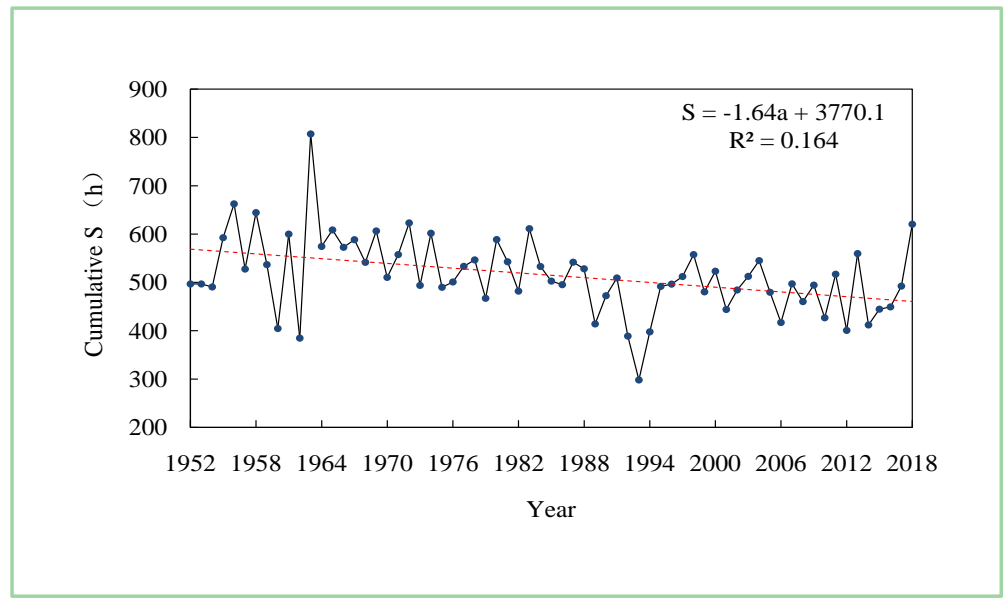

Figure 4. Cumulative sunshine hours in whole field period from 1952 to 2018 in Chenzhou.

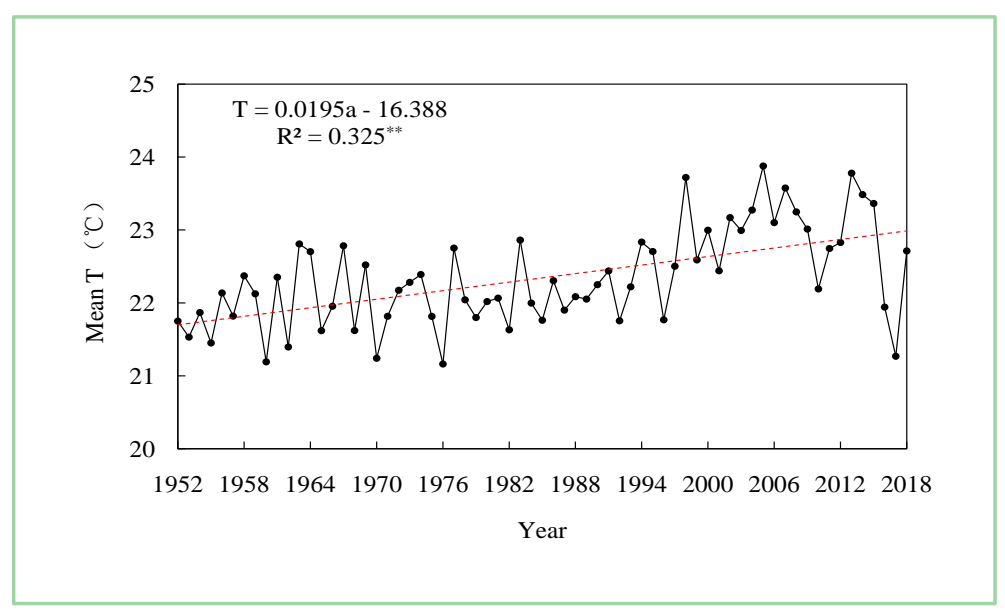

Figure 5. Mean temperature in whole field period from 1952 to 2018 in Chenzhou. 


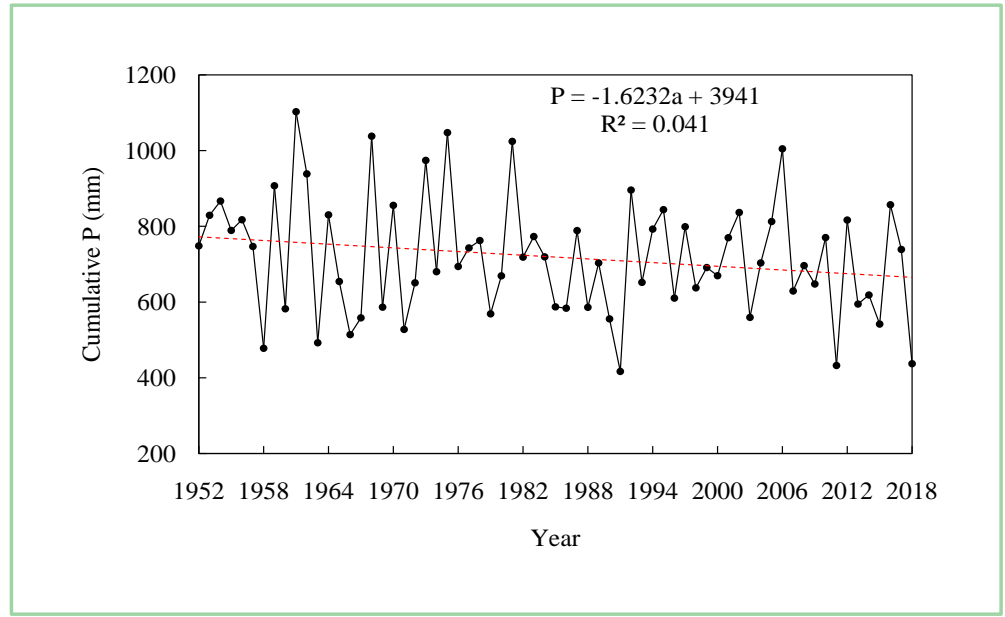

Figure 6. Cumulative precipitation in whole field period from 1952 to 2018 in Chenzhou.

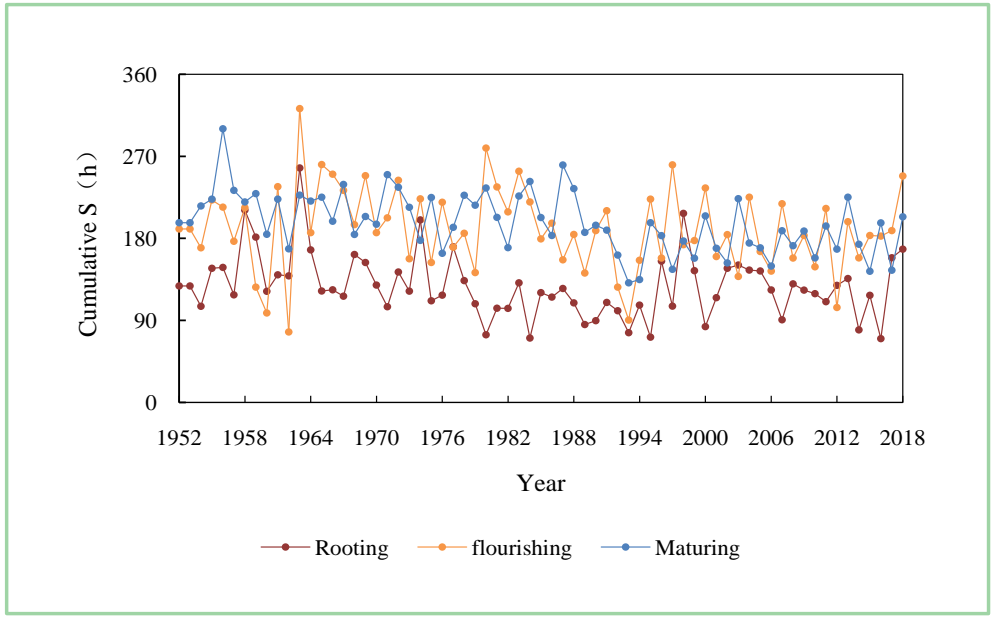

Figure 7. Cumulative sunshine hours in different growing periods of flue-cured tobacco from 1952 to 2018 in Chenzhou.

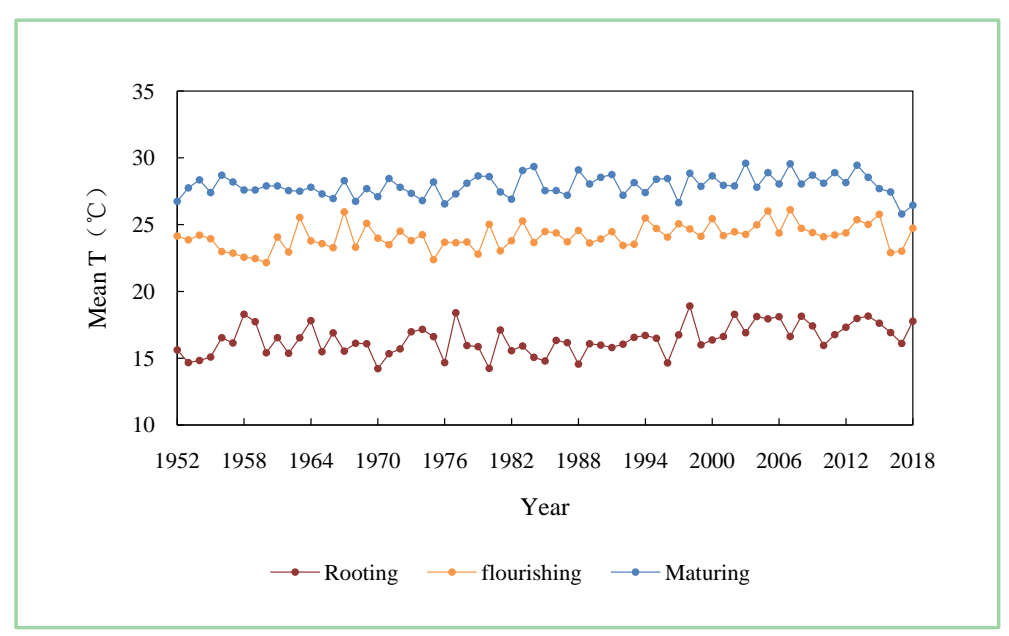

Figure 8. Mean temperature in different growing periods of flue-cured tobacco from 1952 to 2018 in Chenzhou. 


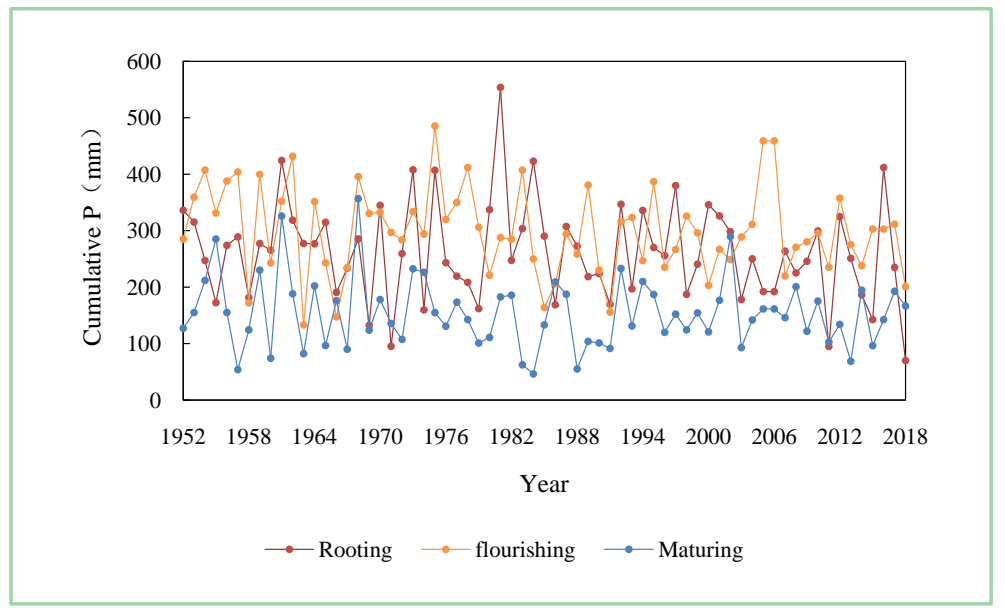

Figure 9. Cumulative precipitation in different growing periods of flue-cured tobacco from 1952 to 2018 in Chenzhou.

Table 2. Optimal regression models of climatic parameters in different field growth periods of flue-cured tobacco in Chenzhou.

\begin{tabular}{ccccc}
\hline Parameter & Growing period & & Model & $R^{2}$ \\
\hline \multirow{2}{*}{$S$} & Rooting & $S$ & $S=\mathrm{e}^{13964.259 / a-2.220}$ & 0.067 \\
& Flourishing & Quadratic & $S=-9.371 \times 10^{-5} \mathrm{a}^{2}+559.714$ & 0.025 \\
& Maturing & Compound & $S=1352021.777 \times 0.996^{a}$ & $0.268^{* *}$ \\
\hline \multirow{2}{*}{$T$} & Rooting & Cubic & $T=2.085 \times 10^{-9} a^{3}$ & 0.180 \\
& Flourishing & Power & $T=a^{1.620}$ & 0.176 \\
& Maturing & Inverse & $T=-35907.895 / a+46.042$ & 0.049 \\
\hline \multirow{2}{*}{$P$} & Rooting & Exponential & $P=340417.270 \mathrm{e}^{-0.004 a}$ & 0.037 \\
& Flourishing & Inverse & $P=2673230.106 / a-1046.993$ & 0.029 \\
& Maturing & Inverse & $P=1506088.953 / a-604.937$ & 0.014 \\
\hline
\end{tabular}

Table 3. Pearson correlation coefficients between climatic parameters.

\begin{tabular}{|c|c|c|c|c|}
\hline \multicolumn{2}{|c|}{ Time } & Parameter & $T$ & $P$ \\
\hline \multirow{2}{*}{\multicolumn{2}{|c|}{ Year }} & $S$ & $-0.251^{\star}$ & $-0.384^{\star \star}$ \\
\hline & & $T$ & I & -0.100 \\
\hline \multirow{2}{*}{\multicolumn{2}{|c|}{ Whole field period }} & $S$ & 0.050 & -0.218 \\
\hline & & $T$ & l & 0.196 \\
\hline \multirow{6}{*}{ Growing period } & \multirow{2}{*}{ Rooting } & $S$ & $0.344^{* *}$ & $-0.259^{*}$ \\
\hline & & $T$ & I & 0.185 \\
\hline & \multirow{2}{*}{ Flourishing } & $S$ & $0.380^{\star *}$ & $-0.404^{\star \star}$ \\
\hline & & $T$ & I & $-0.256^{\star}$ \\
\hline & \multirow{2}{*}{ Maturing } & $S$ & $0.307^{\star}$ & -0.231 \\
\hline & & $T$ & l & $-0.471^{\star *}$ \\
\hline
\end{tabular}

Note: ${ }^{*}$ and ${ }^{* *}$ means correlation is significant in the levels of $p=0.05$ and $p=0.01$ (2-tailed), respectively. 
At the scale of year, cumulative $S$ was negatively significantly correlated with mean $T$ and cumulative $P\left(R=-0.251^{*}, p<0.05 ; R=-0.384^{* *}, p<0.01\right)$, while no significant correlation was found between mean $T$ and cumulative $P$. At the scale of whole field period, no significant correlation was found between the three climatic parameters. In the rooting period, cumulative $S$ was positively significantly correlated with mean $T\left(R=0.344^{* *}, p<0.01\right)$ and negatively significantly correlated with cumulative $P\left(R=-0.259^{*}, p<0.05\right)$, while no significant correlation was found between mean $T$ and cumulative $P$. In the flourishing period, cumulative $S$ was positively significantly correlated with mean $T\left(R=0.380^{* *}, p<0.01\right)$ and negatively significantly correlated with cumulative $P\left(R=-0.404^{* *}, p<0.01\right)$, while negative significant correlation was found between mean $T$ and cumulative $P\left(R=-0.256^{*}, P<0.05\right)$. In the maturing period, cumulative $S$ was positively significantly correlated with mean $T\left(R=0.307^{*}, p<0.05\right)$ but not significantly correlated with cumulative $P$, while negative significant correlation was found between mean $\mathrm{T}$ and cumulative $P\left(R=-0.471^{* *}, p<0.01\right)$.

\subsection{Discussion}

Annual cumulative sunshine hours from 1956 to 2005 in China generally also showed a significant decreasing tendency (annually decreased by $0.012-0.023 \mathrm{~h}$ ) [15], mean temperature from 1951 to 2009 in China also showed a significant increasing tendency (annually increased by $0.005^{\circ} \mathrm{C}-0.008^{\circ} \mathrm{C}$ ) [16], and cumulative precipitation from 1956 to 2015 in southern China showed in general increasing tendency (annually increased by $1.89 \mathrm{~mm}$ ) [17]. The above changing tendencies were also found in Chenzhou in our study, but comparatively, cumulative $S$ in Chenzhou annually decreased by about $7.587 \mathrm{~h}$, mean $T$ annually increased by $0.02^{\circ} \mathrm{C}$, and cumulative $P$ annually increased by $0.184 \mathrm{~mm}$.

As for the changes of climatic parameters during the whole field period of flue-cured tobacco, as literature showed that, during the whole field period of flue-cured tobacco from 1961 to 2010 in Hunan, annual cumulative sunshine hours generally also showed a significant decreasing tendency (annually decreased by $1.08 \mathrm{~h}$ ), cumulative precipitation showed an insignificant increasing tendency (annually increased by $1.5 \mathrm{~mm}$ ) [18], while in Guiyang county of Chenzhou, mean temperature also showed a significant increasing tendency from 1981 to 2010 (annually increased by $0.040^{\circ} \mathrm{C}$ ) [19]. The above changing tendencies were also found in our study, mean $T$ significantly increased with time (annually increased by $0.020^{\circ} \mathrm{C}$ ), while both cumulative $S$ and $P$ insignificantly decreased with time (annually decreased by $1.64 \mathrm{~h}$ and $1.62 \mathrm{~mm}$, respectively). As for the changes of climatic parameters during different growing periods of flue-cured tobacco, as Chen et al. found that, from 1981 to 2010 in Guiyang county of Chenzhou, the average temperature increased in the periods of rooting and flourishing but decreased in the matured period, while precipitation slightly decreased in rooting period but slightly increased in flourishing period [19]. The above tendencies were also found in our study (see Table 2), mean T from 1952 to 2018 in Chenzhou showed an insignificant positive cubic and power functions in the periods of 
rooting and flourishing, but an insignificant negative inverse function in the maturing period, while cumulative $P$ showed an insignificant positive exponential function in the rooting period and insignificant positive inverse function in the periods of flourishing and maturing.

For the whole field period of flue-cured tobacco, the mean of cumulative $S$ was $514.8 \mathrm{~h}$ in Chenzhou, which is in the suitable grade for tobacco planting (500 $600 \mathrm{~h}$ ) but lower than the most suitable grade in Hunan $(\geq 600 \mathrm{~mm})$ [20], moreover, the slight decreasing tendency of cumulative $S$ is disadvantageous for the growth and quality of flue-cured tobacco. The mean of cumulative $P$ was $719.0 \mathrm{~mm}$ in Chenzhou, which is near the lowest value of cumulative precipitation $(700 \mathrm{~mm})$ of the most suitable grade for tobacco planting in Hunan (700 - $800 \mathrm{~mm}$ ) [20], but the slight decreasing tendency of cumulative $P$ is also disadvantageous for the growth and quality of flue-cured tobacco. The cumulative $P$ in the maturing period ranged from $46.4 \mathrm{~mm}$ to $356.8 \mathrm{~mm}$ with a mean of $153.9 \mathrm{~mm}$, which is in or lower than the suitable grade in Hunan $(300-350 \mathrm{~mm})$ [20], so the slight increasing tendency of cumulative $P$ in the maturing period is positive to for the growth and quality of flue-cured tobacco.

\section{Conclusion}

Our study analyzed further the changes of climatic parameters from 1952 to 2018 in Chenzhou city of Hunan province, and the results showed that at the year scale, cumulative sunshine hours showed a significant linear decreasing tendency, mean temperature showed a significant linear increasing tendency, while cumulative precipitation changed irregularly with insignificant increasing tendency. At the scale of whole field period of flue-cured tobacco, mean temperature showed a significant increasing tendency but both cumulative sunshine hours and cumulative precipitation changed irregularly with insignificant decreasing tendency. At the scale of growing periods of flue-cured tobacco, all climatic parameters changed irregularly except cumulative sunshine hours in significant positive compound function in the maturing period. Meanwhile, the slight decreasing tendency of cumulative sunshine hours and the slight increasing tendency of cumulative precipitation were disadvantageous while the slight increasing tendency of cumulative precipitation in the maturing period is positive for the growth and quality of flue-cured tobacco. Further studies are needed to complete the evolution process, valuing research and model optimization of ecological environment in tobacco-growing area in Chenzhou city. Moreover, we should also pay attention to other climatic parameters so that we can make the forecasting application of models more precise.

\section{Acknowledgements}

This study was supported by Chenzhou Tobacco Company of Hunan Province (Grant No. 2019-45). We would like to express thanks to the contribution from all the participants in the data preparation and treatment. 


\section{Conflicts of Interest}

The authors declare no conflicts of interest regarding the publication of this paper.

\section{References}

[1] Luo, D.S., Wang, B. and Qiao, X.Y. (2019) Explanation of National Regionalization of Leaves Style of Flue-Cured Tobacco. Acta Tabacaria Sinica, 25, 1-9. (In Chinese)

[2] Luo, J.Q., Xiao, Y.S., Zhong, Q., et al. (2017) Production Status and Development Countermeasures of Highly Flavored Type Tobacco Leaves in Chenzhou. Hunan Agricultural Sciences, No. 8, 116-118. (In Chinese)

[3] Li, Q. (2000) Researches on the Relationship between Output Value and Yield or Quality of Flue-Cured Tobacco and Their Climatic Types in China. Journal of Anhui Normal University (Natural Science), 23, 72-75. (In Chinese)

[4] Jin, X.Q., Liu, Y.P., Li, Q.J., et al. (2009) Effects of Climatic Conditions on Growth and Development of Flue-Cured Tobacco. Modern Agricultural Science and Technology, No. 4, $135+138$. (In Chinese)

[5] Peng, X.H., Yi, J.H. and Zhou, Q.M. (2009) Advance in Effects of Climatic Conditions on Internal Quality of Flue-Cured Tobacco. Acta Tabacaria Sinica, 30, 68-72. (In Chinese)

[6] Song, Z.M. (2010) Studies on the Main Characters of Flue-Cured Tobacco and Its Relationship with Climatic Factors in Recent Years in China. Institute of Tobacco, Chinese Academy of Agricultural Sciences, Qingdao. (In Chinese)

[7] Wu, Z., Zhu, L.S. and Yi, K. (2011) Research Advance in Effects of Climatic Factors on Chemical Composition of Flue-Cured Tobacco. Acta Agriculturae Jiangxi, 23, 79-82. (In Chinese)

[8] Li, L.Y., Xu, Y.M. and Wang, S.S. (2015) Advance in Effects of Climatic Factors on Aroma Components of Flue-Cured Tobacco. Chinese Tobacco Science, 36, 107-113. (In Chinese)

[9] Kuang, C.F. (2009) Climatic Characteristics and Suitability Assessment on Tobacco-Growing in Chenzhou of Hunan. Modern Agricultural Science and Technology, No. 17, 284-285. (In Chinese)

[10] Rong, K.D. (2013) Analysis of Climatic Resources and Weather Service on Tobacco Production in Chenzhou. Tillage and Cultivation, No. 6, 59-60. (In Chinese)

[11] Chen, Y., Zhou, Q.M., Yang, H.Q., et al. (2015) Analysis of the Climate Characteristics during Field Growth Period of Tobacco in Producing Areas of the Typical Strong Flavor Type Tobacco Leaves in Xiangnan. Chinese Tobacco Science, 36, 56-62. (In Chinese)

[12] Hunan Agriculture Department (1989) Hunan Soils. Agriculture Press, Beijing. (In Chinese)

[13] Chenzhou Municipal Bureau of Statistics (2018) Chenzhou Statistics Yearbook. (In Chinese)

[14] Yu, J.Y. and He, X.X. (2006) Data Statistical Analysis and SPSS Application. Posts \& Telecommunications Press, Beijing. (In Chinese)

[15] Li, H.Q., Fu, Z.T., Wen, X., et al. (2013) Characteristic Analysis of Sunshine Duration Change in China during the Last 50 Years. Climatic and Environmental Research, 18, 203-209. (In Chinese) 
[16] The Second Time National Climate Change Assessment Report Authoring Group (2011) The Second Time the National Climate Change Assessment Report. Science Press, Beijing. (In Chinese)

[17] He, S.L., Guo, X.J., Li, F.Y., et al. (2017) Spatiotemporal Variation of Rainfall and Rainfall Erosivity in Southern China in Recent 60 Years. Resources and Environment in the Yangtze Basin, 26, 1406-1416. (In Chinese)

[18] Zhang, C., Peng L.L., Huang, W., et al. (2012) Influence of Climate Change on Tobacco Planting in Hunan in 1961 to 2010. Journal of Hunan Agricultural University (Natural Sciences), 38, 482-486. (In Chinese) https://doi.org/10.3724/SP.J.1238.2012.00482

[19] Chen, Y., Zhou, Q.M., Yang, H.Q., et al. (2015) Temperature and Precipitation Change in Flue-Cured Tobacco Growing Period in Guiyang and Sangzhi Tobacco-Growing Areas in Hunan Province. Acta Tabacaria Sinica, 21, 48-55.

[20] Xiao, H.Q., Lu, K.D., Zhang, C., et al. (2007) Study on Tobacco Plant Region in Hunan Base on GIS Technology. Journal of Hunan Agricultural University (Natural Sciences), 33, 427-430. (In Chinese) 